\section{International Scientific Journal Theoretical \& Applied Science}

\author{
p-ISSN: 2308-4944 (print) $\quad$ e-ISSN: 2409-0085 (online) \\ Year: $2014 \quad$ Issue: 12 Volume: 20 \\ Published: $30.12 .2014 \quad$ http://www.T-Science.org
}

\section{Zhannura Zharkynbekovna Manapbayeva} Master of Arts, Senior Lecturer at the International Information Technology University,

Kazakhstan jiboj@mail.ru

SECTION 21. Pedagogy. Psychology. Innovations in the field of education.

\title{
DEVELOPMENT OF GENERIC AND SUBJECT-SPECIFIC COMPETENCIES WHILE TEACHING ENGLISH FOR PROFESSIONAL PURPOSES
}

Abstract: This article gives a brief overview of competence-based education. The author presents the way of development of generic and subject-specific competencies based on the lesson plan for English for professional purposes.

Key words: competence-based education, tuning, generic and subject-specific competencies, lesson plan, English for professional users.

Language: English

Citation: Manapbayeva ZZ (2014) DEVELOPMENT OF GENERIC AND SUBJECT-SPECIFIC COMPETENCIES WHILE TEACHING ENGLISH FOR PROFESSIONAL PURPOSES. ISJ Theoretical \& Applied Science 12 (20): 108-110. doi: http://dx.doi.org/10.15863/TAS.2014.12.20.24

Nowadays the distinctive changes in focus, goals, content of education are oriented towards the "free development of the person", creative initiative, self-sufficiency, competitiveness, and mobility of specialists. It is not enough to gain a certain amount of knowledge and master a specific number of skills and abilities for modern students. Time demands from them the ability of self-realization, selfdevelopment, and thinking creatively beyond one subject.

In connection with this educational organizations are updating their teaching methods. The necessity in orientation of education both to acquisition of a certain amount of knowledge and to development of personality, cognitive, creative, and communicative abilities of the students has been emphasized in the new educational standards.

Educational organizations are to develop an integral system of universal knowledge, abilities, and skills, as well as self-sufficiency and personal responsibility of the students, i.e. key competencies, which define the modern quality of education. "Competency-based learning is an approach to teaching and learning more often used in learning concrete skills than abstract learning. It differs from other non-related approaches in that the unit of learning is extremely fine grained. Rather than a course or a module every individual skill/learning outcome, known as a competency, is one single unit" [1]. In general, two sets of competencies are identified: general (generic) competencies that are implemented in every field of knowledge and specific competencies that are specific to certain fields of knowledge. The development of specific knowledge and skills is considered a basis of study programmes, but the development of general (generic) competencies is very important in training students for the job market and their future role in society [8].

Extending the use of competence-based quality tools for planning and delivery of degree programmes is one of the main aims of the project "Towards a Central Asian Higher Education Area: Tuning Structures and Building Quality Culture" (TuCAHEA). It is a Tempus Structural Measures project which will run from 15 October 2012 to 14 October 2015. There are 47 partners, including 8 European Union Universities, 34 Central Asian Universities, and the Ministries of Education of the five partner countries (Kazakhstan, Kyrgyzstan, Tajikistan, Turkmenistan and Uzbekistan [2]. Besides, the project aims to foster student mobility within and outside the region and tests and perfects the quality and recognition tools necessary for mobility; to establish information/dissemination centers in both capitals and other areas of the partner countries.

The principal outcomes will be to extend knowledge of the worldwide Tuning process, involving the Central Asian area directly in Tuning's 
broad international context; to enhance knowledge of existing quality and recognition tools as a basis for further elaboration; to carry out consultations on both generic and subject specific competences, to produce a number of Tuning Subject Area reports; to produce competence/learning-outcomes-based descriptions of degree programmes using the Degree Profile template developed by Tuning and the ENIC-NARIC Network, and more generally to creating a basis for a Central Asian Higher Education Area, developing premises for a Central Asian Qualifications Framework and Credit System [3].

The first plenary session of consortium within the framework of the above-mentioned project was held at International Information Technology University in Almaty, Kazakhstan. The participants of the plenary meeting discussed and approved the list of generic competences for Central Asia, discussed specific competences on 8 subject areas, and hold a meeting on development of competencebased method in educational directions of the university. In May and June of the same year there were consultations with undergraduate, graduate students, university teachers and employers on the relevance of the suggested generic and specific competences. The consultations were carried out through online survey with the list of competences [3]. The results of the survey revealed the list of competences which are equally important for participants.

The next question is to apply the development of these competencies in lessons, i.e. to show how to teach, form, and develop the competencies in students. For this purpose we would like to present a detailed lesson plan on the topic "Netiquette" with exercises to form generic and subject-specific competencies while teaching English for computer users. The duration of the lesson is 50 minutes. The subject the lesson is given in is called English for Professional Purposes for students majoring Information Technologies, Computer Science and Software Engineering, Computer Science, Mathematical Computer Modelling, Radioelectronics, Electronics and Telecommunications, Finance in IT, and Electronic Journalism. The lesson is aimed at students with PreIntermediate level of English.

In most lesson plans you will find the following aims and objectives of the lesson: to enlarge students' vocabulary on the topic "Netiquette" and to develop listening and speaking skills. Besides, you will find a list of learning outcomes as follows: by the end of the lesson Ss will be able to use vocabulary related to the topic "Netiquette"; say netiquette rules; understand authentic speech on the topic "Netiquette". In competence-based learning teachers either replace these lists of aims and learning outcomes or add an extra list of generic and specific competences to be developed. We shall also present the list of generic and language-specific competencies for our lesson at the end of the article.

At the beginning of the lesson students guess the meaning of the word "Netiquette", give examples of netiquette rules, if any. We consider that this activity develops the competency such as ability to use the studied language in practical situations as the students discuss the given topic.

The main part of the lesson consists of three parts: "What is netiquette?" "Netiquette rules", and "Am I a good cyber citizen?" In the first part students do some pre-teaching vocabulary activity and watch a video by Julie Spira "What is netiquette?" and the following exercises [4]:

1. As you watch mark sentences True or False.

1. There are over 2 million users on the Internet.

2. The World Wide Web has now become the wild, wild west.

3. Netiquette considers only e-mail communication.

4. You need to follow netiquette to protect your digital reputation.

5. Don't treat people the way you want to be treated.

2. Compare your definition with the one presented in the video.

At this stage of the lesson we can emphasize on the development of such competency such as ability to search, retrieve, analyze and process the information in the studied language.

The next part of the lesson will be based on speaking skills. Student will be given vocabulary exercises to pre-learn the words, and do the following exercise:

3. Make some netiquette rules with your partner(s). Show your rules to other students. Vote as a class on what the best rules are.

Table 1

\begin{tabular}{|l|l|l|}
\hline You... & should & shouldn't \\
\hline ask permission before posting about someone or something & & \\
\hline ask permission before sharing email, photo or chat conversation & & \\
\hline post personal information (for example, about your problems) & & \\
\hline use all capital letters in messages & & \\
\hline use emoticons (smileys) appropriately & & \\
\hline
\end{tabular}




\begin{tabular}{|l|l|l|}
\hline check for typos and other mistakes & & \\
\hline use acronyms (like LOL, BTW) & & \\
\hline avoid sarcasm & & \\
\hline be polite and respectful & & \\
\hline spam people & & \\
\hline abuse people & & \\
\hline be a better person if somebody is rude to you & & \\
\hline ignore cyber bullies & & \\
\hline send something you wouldn't say directly to someone's face & & \\
\hline plagiarize & & \\
\hline obey copyright laws & & \\
\hline engage in flame wars & & \\
\hline be anonymous & & \\
\hline install antivirus software & & \\
\hline
\end{tabular}

The list of these do's and don'ts have been generated by the teacher using several resources [5; 6]. This activity shall help in teaching specific competencies as ability to communicate in the studied language in different situations (general, business, academic, professional and multilingual).

In the following stage students develop some general competencies while describing pictures about netiquette rules, talk to their partners, and say whether their partner is a good cyber citizen. They learn how to apply logical and critical thinking to solve problems, to analyze and synthesize, etc.

The home task given after this lesson consists of an online quiz "Are you a great cyber citizen?" [7]. Students do the quiz at home, and come to class with their impressions about the quiz, which will lead to a discussion.

Apart from the above mentioned competencies, some other generic and subject specific abilities can be trained during the lesson, since the topic has been selected successfully, and it teaches knowledge of the social and historical aspects necessary to learn and use a foreign language, ability to communicate in multicultural environment, social responsibility, ability to avoid and manage conflicts, ability to be tolerant and respectful towards others, and ability to be flexible.

Competencies will help organize teaching process in a way that it will be effective, helpful, and interesting for undergraduate, graduate students, university teachers and employers. The importance of competence-based teaching can also be seen in the fact that many European universities after the implementation of the Bologna Declaration have reformed or are in a process of developing and reforming their curricula in relation to competencies, in order to ensure that the graduates of these universities will reach higher quotas of employability and also increase their competitiveness on the international job market [8]. Therefore, study programmes should have their lists of competencies including two sets of competencies and specific competences that students need to acquire during their studies. In this way, competence-based teaching means being able to implement the acquired knowledge and skills in a specific context.

\section{References:}

1. (2014) Competency-based learning. Available: http://en.wikipedia.org/wiki/Competencybased learning (Accessed: 30 December 2014).

2. (2014) "Towards a Central Asian Higher Education Area: Tuning Structures and Building Quality Culture". Available: http://www.tucahea.org/ (Accessed: 30 December 2014).

3. (2014) Tempus. Available: http://www.iitu.kz/lang/kz/page/tempus.html (Accessed: 30 December 2014).

4. (2014) Julie Spira "What is netiquette? and Why is it important?" Available: http://www.youtube.com/watch?v=gvkbDc1Li VI (Accessed: 30 December 2014).
5. (2014) The rules of Netiquette. Available: http://www.networketiquette.net/netiquette.htm (Accessed: 30 December 2014).

6. (2014) Netiquette rules. Available: http://www.buzzle.com/articles/netiquetterules.html (Accessed: 30 December 2014).

7. (2014) Online quiz "Are you a great cyber citizen?" Available: http://www.carnegiecyberacademy.com/funStuf f/netiquette/netiquette.html (Accessed: 30 December 2014).

8. Beinhauer R, Suh I, Tahiri L (2014) Competence-based teaching and research in higher education. Prishtina, 2014. 